\title{
An HNSCC syngeneic mouse model for tumor immunology research and preclinical evaluation
}

\author{
YOU FU ${ }^{1,2^{*}}$, GUOCAI TIAN ${ }^{1,2^{*}},{\text { JIANG } \mathrm{LI}^{1,3} \text {, ZHIYUAN ZHANG }}^{1,2}$ and $\mathrm{KE} \mathrm{XU}^{1,2}$ \\ ${ }^{1}$ Shanghai Key Laboratory of Stomatology, Shanghai Jiao Tong University School of Medicine; \\ Departments of ${ }^{2}$ Oral and Maxillofacial-Head Neck Oncology, and ${ }^{3}$ Oral Pathology, Shanghai Ninth People's Hospital, \\ Shanghai Jiao Tong University School of Medicine, Shanghai 200011, P.R. China
}

Received October 30, 2019; Accepted May 27, 2020

DOI: $10.3892 / \mathrm{ijmm} .2020 .4680$

\begin{abstract}
The lack of reliable animal models to assess the safety and efficacy of drugs and to explore the underlying molecular mechanisms is one of the most severe impediments in head and neck squamous cell carcinoma (HNSCC) tumor immunology research. The majority of xenograft tumor models established using immunodeficient mice neglect the effects of $\mathrm{T}$ cells. To date, to the best of our knowledge, there is no syngeneic tumor model available that reflects the immune microenvironmental features of HNSCC tumors. To solve this issue, the present study used 4-nitroquinoline-1-oxide (4-NQO) to induce squamous cell carcinoma in C57BL/6 mice. Three HNSCC cell lines were then established, and one of these, termed JC1, was selected for further analysis due to its enhanced proliferative ability and tumorigenicity in immunodeficient nude mice. However, none of the 3 cell lines could form tumors in immunocompetent mice. Due to the different tumorigenicities in nude and C57BL/6 mice, the immune system may play an important role in inoculated JC1 tumor progression. Chemical induction was used to establish the tumorigenicity-enhanced cell line, JC1-2, which can form syngeneic tumors in immunocompetent C57BL/6 mice. Next-generation sequencing (NGS) was used to perform the immunogenomic and transcriptomic characterization of the JC1-2 cells. Splenocytes were isolated from C57BL/6 mice and co-cultured with JC1-2 cells to verify the responsiveness of the
\end{abstract}

Correspondence to: Professor Zhiyuan Zhang or Dr Ke Xu, Department of Oral and Maxillofacial-Head Neck Oncology, Shanghai Ninth People's Hospital, Shanghai Jiao Tong University School of Medicine, 639 Zhizaoju Road, Shanghai 200011, P.R. China

E-mail: zhzhy@sjtu.edu.cn

E-mail:xuke131@shsmu.edu.cn

*Contributed equally

Key words: syngeneic immunocompetent mouse model, next-generation sequencing, co-culture, tumor immune microenvironment, multiplex immunohistochemistry interferon (IFN)- $\gamma$ pathway in the JC1-2 cell line. Unlike the majority of syngeneic mouse tumors, the JC1-2-formed tumors resembled 'inflamed tumors' due to the abundancy of immune cells in the tumor microenvironment. Moreover, more intense immune responses were observed in the orthotopic mouse model than in the heterotopic model. Thus, this model could be used to delineate the interactions between HNSCC and lymphocytes, and to validate novel immunotherapy targets.

\section{Introduction}

Head and neck cancers involve the formation of tumors originating from any tissue or organ in the head and neck, apart from the eyes, brain, ears, thyroid and esophagus, including neck tumors, otolaryngological tumors, and oral and maxillofacial tumors. Head and neck cancer is the 6th most common malignancy worldwide $(1,2)$, and, $90 \%$ of cases are head and neck squamous cell carcinoma (HNSCC) cases. With the development of surgery, chemotherapy, radiation therapy, targeted therapy and multidisciplinary sequential therapy, the quality of life of patients with HNSCC has improved to a certain extent. However, the 5-year survival rate of patients with HNSCC remains low compared to that of patients with other malignant cancers, such as cervical and breast cancers (3). Recurrence, distant metastasis and drug resistance are the main obstacles to the treatment of oral squamous carcinoma (4). In recent years, immunotherapy has provided new treatment options for patients with head and neck cancers (5). Nonetheless, the lack of a proper model linking immunology research with clinical diagnosis and treatment strategies severely hampers the development of novel antitumor immunotherapies and drugs (6).

4-Nitroquinoline-1-oxide (4-NQO) is a potent chemical carcinogen. It has been extensively used in both rats and mice (7-9) and is useful for studies on the mechanisms and progression of HNSCC $(10,11)$. Long-term repeated exposure to carcinogens is widely considered to be one of the most common risk factors of HNSCC. The 4-NQO-induced tumor model requires several months to establish, and the process is similar to the process of human HNSCC. 4-NQO can cause NADPH-catalyzed DNA damage. NADPH quinone oxidoreductase is abundantly expressed in the tongue mucosa. As a result, the progression of tumors induced by $4-\mathrm{NQO}$ can aptly mimic the progression of human cancers, and the mouse model 
of 4-NQO-induced tumors may be an ideal tool for the study of the molecular mechanisms of HNSCC. Additionally, such a mouse model provides a platform for investigating the molecular mechanisms of and therapeutic strategies for HNSCC. However, the mouse model of 4-NQO-induced tumors is time-consuming to establish and cannot be easily repeated.

Immunotherapy is a significant part of malignancy therapy, which highlights the importance of research on the mechanisms of tumor immunology for successful clinical translation (12). However, obstacles to such research exist; for example, there only a limited number of proper animal models for immunological research in vivo, and experiments in vitro have limitations that can cause drug resistance and relapse (13). As a result, a reliable mouse model is urgently required for tumor immunology studies (14).

Microsatellites (MSs) are ubiquitous in the human genome and are mostly located in the non-coding regions of genes, and the proximal telomere regions of chromosomes. Currently, it is considered that MSs play an important role in maintaining genomic stability and regulating gene expression. Microsatellite instability (MSI) is characterized by the existence of different numbers of replicated units of the same MS locus between different individuals or between normal and abnormal tissues in the same individual. The loss of heterozygosity $(\mathrm{LOH})$ is characterized by the loss of a normal allele from a region of one chromosome of a pair, which allows a defective allele on the homologous chromosome to cause clinical manifestations. LOH is generally associated with tumor suppressor genes (such as p53), which inhibit the occurrence of malignant tumors when both alleles are present. When one allele is clearly abnormal or missing (and the other is already inactive) and no longer inhibits malignancy, normal cells become malignant. However, the mechanisms of genetic aberrations, such as MSI and LOH remain unclear in HNSCC. According to the method of $\mathrm{LOH}$ analysis described previously (15), the degree of $\mathrm{LOH}$ was determined to exclude the possibility that clones may have lost neoantigen-generating mutations and the results revealed that there were no $\mathrm{LOH}$ events at the genomic positions of the neoantigens, suggesting that no neoantigens were lost owing to $\mathrm{LOH}$.

In the present study, the tumorigenic HNSCC cell line ' $\mathrm{JCl}$ ' and the tumorigenicity-enhanced cell line 'JC1-2' were established. Transplanted tumors derived from JC1 cells could only grow in immunodeficient nude mice, while tumors derived from JC1-2 cells could grow in immunocompetent C57BL/6 mice. Next-generation sequencing (NGS) technologies were used to characterize the JC1 and JC1-2 cells, and it was verified that both cell lines had an MS stability (MSS) phenotype and a responsive interferon (IFN) $-\gamma$ pathway. Orthotopic and heterotopic mouse tumor models of JC1-2 cells were established and more intense immune responses were observed in the microenvironment of the orthotopic model. This syngeneic model may thus enable the better delineation of interactions between HNSCC and lymphocytes and the exploration of potential therapeutic targets for HNSCC.

\section{Materials and methods}

Animals and primary culture of the HNSCC cell lines. All C57BL/6 mice used in the present study $(n=58$; weighing
16-22 g, 6 weeks old) had ad libitum access to sterile food and water and were maintained in a stable environment under constant temperature and humidity $\left(22 \pm 5^{\circ} \mathrm{C}\right.$, $60 \pm 3 \%$ humidity) with a 12 -h light-dark cycle. In the experiments, all mice were female to avoid the antigenic diversity resulting from any sex differences. 4-NQO (Sigma-Aldrich; Merck KGaA) at a concentration of $120 \mu \mathrm{g} / \mathrm{ml}$ (we selected 80,100 and $120 \mu \mathrm{g} / \mathrm{ml}$ as the preliminary experimental dose of 4-NQO, due to the high tumor formation rate and low mouse death rate, $120 \mu \mathrm{g} / \mathrm{ml}$ was selected) was added to the drinking water of the mice $(n=20)$ for 20 weeks (the animal bedding and water were changed every week). In total, 3 of these 20 mice (15\%) died during this experiment (possibly due to drug toxicity) (16), and the surviving animals were observed for an additional 4 weeks prior to sacrifice. All the mice were observed and weighed once every 3 days to monitor their health. Tumors were measured once a week. Once the volumes of tumors were $>1,000 \mathrm{~mm}^{3}$, the mice were euthanized with $100 \%$ compressed $\mathrm{CO}_{2}$ gas at a flow rate of $20 \%$ chamber $\mathrm{vol} / \mathrm{min}$. In addition, 5 C57BL $/ 6$ mice were provided with normal drinking water as the normal controls (to observe the appearances and pathological manifestations of normal mucosal tissues). A strict criterion for humane endpoints was used as follows: i) weight loss $>15 \%$ for $72 \mathrm{~h}$; ii) severe dehydration; iii) sluggish behaviors (inability to eat or drink); iv) arching back or lateral decubitus; and v) inability to move normally as the tumor was too large $\left(>1,000 \mathrm{~mm}^{3}\right)$ or for other reasons. Once a mouse was found to exhibit any of the above symptoms, it would be euthanized with $100 \%$ compressed $\mathrm{CO}_{2}$ gas at a flow rate of $20 \%$ chamber $\mathrm{vol} / \mathrm{min}$ for $7 \mathrm{~min}$. The death of the mice was verified by the assurance of cessation of respiratory and cardiovascular movements by observation at room air for at least $10 \mathrm{~min}$. All animal experiments were approved by and performed in accordance with the guidelines of the Shanghai Jiao Tong University School of Medicine.

After 24 weeks, all mice were sacrificed, and oral tumors (mostly on the tongue, some were on the cheeks and mouth floor) were collected from the mice for further cell line establishment. Fresh tongue tumor samples were selected and cut into sections $\left(0.5 \mathrm{~mm}^{3}\right)$, after which they were incubated at $37^{\circ} \mathrm{C}$. A limiting dilution assay was applied to screen monoclonal HNSCC cells, and the largest colonies were kept for further culture. After 20 passages, the murine HNSCC cell lines were considered to have been established. A total of 15 athymic nude mice were used to examine the tumorigenicity of 3 cell lines. Cell morphology was examined under a microscope (ZEISS Axioscope 5). The 3 HNSCC cell lines, named JC1, JC2 and JC3, were then established, and one of these, termed JC1, was selected for further analysis due to its enhanced proliferative ability and tumorigenicity in immunodeficient nude mice (data not shown).

$\mathrm{JC} 1$ cells were incubated with 4-NQO $(0.1 \mu \mathrm{g} / \mathrm{ml})$ for $24 \mathrm{~h}$ and the treated cells were then inoculated into immunocompetent C57BL/6 mice. Successfully growing tumors (tumor formation rate, approximately $30 \%$ ) were collected, primary culture was applied, and a new cell line, termed JC1-2, was established.

Following the anesthetization of the mice with pentobarbital (Sigma-Aldrich; Merck KGaA, diluted in saline, $75 \mathrm{mg} / \mathrm{kg}$ 
injected intraperitoneally), $5 \times 10^{6} \mathrm{JC} 1-2$ cells were injected carefully into the cheeks and underneath the skin of the backs of the mice using a 27-gauge needle to establish orthotopic and heterotopic tumor models. A total of 12 C57BL/6 mice were involved and sacrificed when the tumor dimension was $>1,000 \mathrm{~mm}^{3}$. The mouse melanoma cell line B16 (TCM 2), mouse colorectal cancer cell line CT26 (TCM37) and the mouse breast cancer cell line 4T1 (TCM32) were purchased from the Chinese Academy of Sciences Cell Bank/Stem Cell Bank. The mouse squamous cell line, SCC7, was a generous gift from Professor Zhuang Liu [Institute of Functional Nano and Soft Materials (FUNSOM), Collaborative Innovation Center of Suzhou Nano Science and Technology, Soochow University]. A total of $1 \times 10^{6}$ cells were injected carefully underneath the skins of the backs of the mice (B16 cells, C57BL/6 mice; CT26 and 4T1 cells, BALB/c mice; SCC7 cells, $\mathrm{C} 3 \mathrm{H}$ mice) using a 27 -gauge needle to establish transplanted tumor models (3, 6-week-old female mice weighing 16-22 $\mathrm{g}$ were used for each different type of mouse). All mice were provided with ad libitum access to sterile food and water and were maintained in a stable environment under constant temperature and humidity $\left(22 \pm 5^{\circ} \mathrm{C}, 60 \pm 3 \%\right.$ humidity) with a 12-h light-dark cycle. Tumors were measured once a week. Once the volumes of tumors were $>1,000 \mathrm{~mm}^{3}$, the mice were euthanized with $100 \%$ compressed $\mathrm{CO}_{2}$ gas at a flow rate of $20 \%$ chamber vol $/ \mathrm{min}$ for $7 \mathrm{~min}$. The death of the mice was verified by the assurance of cessation of respiratory and cardiovascular movements by observation at room air for at least $10 \mathrm{~min}$. All tumor samples were fixed with formalin and embedded in paraffin for further staining.

Immunohistochemical and immunofluorescence staining. Murine tumor samples were fixed with paraformaldehyde (Sangon Biotech) and embedded in paraffin. The slides (3- $\mu$ m-thick) of the formalin-fixed paraffin-embedded (FFPE) samples were then used for staining. Slides were incubated with primary antibodies (Abs) against the following proteins at $37^{\circ} \mathrm{C}$ for $1 \mathrm{~h}$ : Anti-pan cytokeratin (CK-Pan; 1:400 dilution, ab7753, Abcam), Ki-67 (1:400 dilution, 9449s, Cell Signaling Technology, Inc.) and vimentin (1:1,000 dilution, 10366-1-AP, Proteintech) $\beta$-2-microglobulin (B2m; 1:4,000 dilution, ab218230, Abcam) and with HRP-conjugated goat anti-rabbit IgG secondary antibody $(1: 250, \mathrm{ab} 7090, \mathrm{Abcam})$ at $37^{\circ} \mathrm{C}$ for $30 \mathrm{~min}$. The HNSCC samples were stained with hematoxylin (abs9139 Absin Bioscience, Inc.) and eosin (abs9222, Absin Bioscience, Inc.) (H\&E). Normal tongues from the control group were used as control samples. All IHC images were examined with a microscope (ZEISS Axioscope 5).

After the slides were stained with primary ( $\beta$-2-microglobulin, B2m; 1:4,000 dilution, ab218230, Abcam; $\left.45 \mathrm{~min}, 37^{\circ} \mathrm{C}\right)$ and secondary antibodies (1:250, ab7090, Abcam; $30 \mathrm{~min}, 37^{\circ} \mathrm{C}$ ), a tyramide (TSA)-conjugated fluorophore (NEL791001KT, Perkin Elmer; T20950, Life Technologies; Thermo Fisher Scientific, Inc.) was added to the slides at a 1:100 dilution in amplification buffer (NEL791001KT, Perkin Elmer). The slides were incubated for $10 \mathrm{~min}$ at room temperature and then washed with PBS 3 times. Finally, the slides were stained with DAPI (40728ES50, Yeasen) and incubated in $37^{\circ} \mathrm{C}$ for $3 \mathrm{~min}$. The slides were imaged by Zeiss Axio Scan $\mathrm{Z} 1$ and analyzed using ZEISS imaging software ZEN lite.
Exome and RNA sequencing and data analysis. Total DNA was isolated from the JC1 and JC1-2 cells using an AllPrep DNA/RNA Mini kit (Qiagen $\mathrm{GmbH}$ ). Library preparations and sequencing were performed at Shanghai Biotechnology Corporation. Syngeneic mouse normal mucosal exomes and JC1 and JC1-2 cell samples were collected and sequenced with an Illumina HiSeq 2500 platform. The variant analysis was performed using GATK developed by Broad Institute which primarily focuses on SNPs and INDELs $(17,18)$. For RNA sequencing, total RNA was extracted using TRIzol reagent (Invitrogen; Thermo Fisher Scientific, Inc.), and the quality was verified. An nCounter Analysis System (NanoString Technologies) was used to screen for significantly differentially expressed genes. The purified mRNA was subsequently fragmented into sizes of 200-500 bp. An Illumina HiSeqTM 2000 was used for cDNA library paired-end sequencing. The cDNA libraries were subjected to library quantification prior to cluster generation. Paired end 2,650 bp sequencing runs were performed to align the cDNA sequences to the mouse $\mathrm{mm} 9$ reference genome. Potential mutated peptides resulting from non-synonymous mutations were analyzed to predict their binding affinity to the major histocompatibility complex class I (Mhc-I) alleles $\mathrm{H}-2 \mathrm{~Kb}$ and $\mathrm{H}-2 \mathrm{Db}$. A binding affinity $<500 \mathrm{nM}$ was considered to indicate strong binding. A mutation was defined as expressed if the normalized counts of the corresponding gene were $>10$. The pheatmap package in $\mathrm{R}$ (version 3.2.0) was employed to conduct the bidirectional hierarchical clustering. String v11.0 (https://string-db.org/) and CytoScape (http://www. cytoscape.org/) were used to illustrate functional interactions among the differential expression genes (DEGs). The Gene Ontology (GO, http://geneontology.org/) and Kyoto Encyclopedia of Genes and Genomes (KEGG, https://www. genome.jp/kegg/) databases were used for further pathway and function enrichment analysis. Protein-protein analyses were performed to reveal the network of the differentially expressed genes based on the interactions among the genes, proteins and compounds included in the KEGG database. Lollipops-v1.3.2 (https://github.com/pbnjay/lollipops/releases/tag/v1.3.2) was used to show point locations of specific genes in the genomic region.

Co-culture of JC1-2 cells and splenocytes. A total of 6 female C57BL/6 mice were euthanized with $100 \%$ compressed $\mathrm{CO}_{2}$ gas and splenocytes were isolated. The spleens were ground repeatedly and filtered twice. Following suspension and centrifugation at $400 \mathrm{x} \mathrm{g}$ at $4^{\circ} \mathrm{C}$ for $10 \mathrm{~min}$, the cells were washed twice with PBS and centrifuged at $400 \mathrm{x}$ g at $4^{\circ} \mathrm{C}$ for $15 \mathrm{~min}$ to isolate the mononuclear cell layer.

For indirect co-culture experiments, $1.0 \mu \mathrm{m}$ pore size Millicell Hanging Cell Culture Inserts (EMD Millipore) were placed on top of the JC1-2 cells that had been previously plated. The splenocytes were seeded onto the insert at a density of $1 \times 10^{7}$ cells per insert. The JC1-2 cells had no direct contact with the splenocytes when the inserts were used in this manner (Fig. 3A). IFN- $\gamma$ (Sigma-Aldrich; Merck KGaA) was used at a concentration of $10 \mathrm{ng} / \mathrm{ml}$ for $48 \mathrm{~h}$.

In direct co-culture experiments, the splenocytes ( $1 \times 10^{7}$ cells per well) were directly added to JC1-2 cells $\left(5 \times 10^{5}\right.$ cells per well). A BD IMag ${ }^{\mathrm{TM}}$ Mouse T Lymphocyte 
Enrichment Set-DM kit (BD Biosciences) was used to isolate $\mathrm{CD}^{+} \mathrm{T}$ lymphocytes and other non-CD3 ${ }^{+}$splenocytes. $\mathrm{CD}^{+}$ $\mathrm{T}$ lymphocytes and non- $\mathrm{CD}^{+}$splenocytes were added at a density of $1 \times 10^{7}$ cells per well.

JC1-2 cells were digested and resuspended at a concentration of $1 \times 10^{6}$ cells $/ \mathrm{ml}$. All plates were incubated at $37^{\circ} \mathrm{C}$ for $6 \mathrm{~h}$ to allow cell adherence, and the culture medium was then discarded and replaced with $1 \mathrm{ml}$ of fresh medium. After 4 days, all wells contents were collected for analysis.

Flow cytometry and reverse transcription-quantitative polymerase chain reaction ( $R T-q P C R)$ analysis of Mhc I and PD-L1 expression in JC1-2 cells. JC1-2 cells were collected, $1 \times 10^{6}$ cells were suspended, and $2 \mu \mathrm{l}$ of Fc block (BD Biosciences) was added. The cells were washed with PBS twice, resuspended in $1 \mathrm{ml}$ of PBS with $1 \%$ FBS and then incubated at $37^{\circ} \mathrm{C}$ for 45 min with antibodies against PE-MHC-I (562004, BD Biosciences) and APC-PD-L1 (564715, BD Biosciences). The cells were again washed with PBS and resuspended in $500 \mu \mathrm{l}$ of BD stain buffer, and the different positive cells were analyzed with a BD FACSCanto flow cytometer (BD Biosciences). To examine the cell cycle of JC1-2 cells, the cells were incubated at $4^{\circ} \mathrm{C}$ for 20 min with Propidium Iodide Staining Solution (556463, BD Biosciences) prior to flow cytometry.

A total $1 \times 10^{6}$ cells were harvested for RT-qPCR analysis. Total RNA was extracted using TRIzol reagent (Invitrogen; Thermo Fisher Scientific, Inc.), and cDNA was synthesized using SuperScript IV (Invitrogen; Thermo Fisher Scientific, Inc.) following the manufacturer's instructions. The mRNA expression of Mhc-I was measured by RT-qPCR using the StepOnePlus ${ }^{\mathrm{TM}}$ Real-Time PCR System (4376600; Thermo Fisher Scientific, Inc.) using SYBR-Green (Takara Biotechnology Co., Ltd.) technology. The thermocycling conditions were as follows: $95^{\circ} \mathrm{C}$ for $30 \mathrm{sec}$, then 30 cycles of $95^{\circ} \mathrm{C}$ for $5 \mathrm{sec}, 60^{\circ} \mathrm{C}$ for $30 \mathrm{sec}$ ). The Mhc-I primer sequences were as follows: Forward, 5'-AGGACATGGAGCTTGTGG AGACC-3' and reverse, 5'-TGTTGGAGACAGTGGATGGA GGA-3'. GAPDH was used as an internal control. The EGFR primer sequences were as follows: Forward, 5'-TCCTGATTG GTGCTGTGCGATTC-3' and reverse, 5'-CTGGCAGTTCTC CTCTCCTCCTC-3'. The GAPDH primer sequences were as follows: Forward, 5'-GGTTGTCTCCTGCGACTTCA-3' and reverse, 5'-TGGTCCAGGGTTTCTTACTCC-3'. The average cycle threshold $(\mathrm{Ct})$ value of each group was calculated, and the $\mathrm{Ct}$ value of the control group was subtracted to determine the $\Delta \mathrm{Ct}$ value. The mRNA expression levels of Mhc-I and PD-L1 mRNA was calculated by using the $2^{-\Delta \Delta \mathrm{Cq}}$ method (19). The values for the control group were set as 1 , and the values for the other groups were calculated as the fold changes relative to the control values.

Multiplex fluorescent immunohistochemistry (IHC) for immune cell markers in tumor samples. Murine tumor samples were fixed with paraformaldehyde (Sangon Biotech). After the slides were stained with primary (CD3, 1:200 dilution, ab16669, Abcam; CD8, 1:400 dilution, 98941, Cell Signaling Technology, Inc.; and PD-1, 1:400 dilution, ab214421, Abcam; $\left.45 \mathrm{~min}, 37^{\circ} \mathrm{C}\right)$ and secondary antibodies $\left(30 \mathrm{~min}, 37^{\circ} \mathrm{C}\right)$, a tyramide (TSA)-conjugated fluorophore (NEL791001KT,
PerkinElmer; T20950, Life Technologies) was added to the slides at a 1:100 dilution in amplification buffer (NEL791001KT, PerkinElmer). The slides were incubated for $10 \mathrm{~min}$ at room temperature and then washed with PBS 3 times. This step was followed by heat-mediated $\mathrm{Ag}$ stripping $[0.1 \mathrm{M}$ glycine (G2879, Sigma-Aldrich; Merck KGaA), adjusted to $\mathrm{pH} 10$ using $\mathrm{NaOH}$ (795429, Sigma-Aldrich; Merck KGaA) and $0.5 \%$ Tween] to remove the primary antibody for labeling with the appropriate primary antibody. Finally, slides were added DAPI (40728ES50, Yeasen) and incubated in $37^{\circ} \mathrm{C}$ for $3 \mathrm{~min}$. The slides were imaged by Zeiss Axio Scan Z1 and analyzed using ZEISS imaging software ZEN lite.

Statistical analysis. The data are presented as the means \pm SD. One-way or two-way analysis of variance (ANOVA) followed by Tukey's post hoc test was performed to identify any significant differences. A computer-based statistical package (SPSS, version 22.0) was utilized for the analysis. $\mathrm{P}<0.05$ was considered to indicate a statistically significant difference.

\section{Results}

Successful establishment of mouse models of 4-NQO-induced HNSCC and murine HNSCC cell lines. All the tumor samples from the mice in the 4-NQO-induced tumor model were positive for $\mathrm{CK}$ and $\mathrm{Ki}-67$, which confirmed that the tumors were of epithelial origin (Fig. S1A). Considering that the 4-NQO-induced mouse tumor models are time-consuming to establish and unrepeatable, more convenient and replicable models are required. In the present study, mouse tumor samples were collected and primary culture was applied to acquire murine-derived HNSCC cell lines. All the 3 cell lines exhibited tumorigenicity in athymic nude mice (data not shown). However, the transplanted tumors of all 3 cell lines could not grow in immunocompetent C57BL/6 mice $(n>10)$. Once inoculated into C57BL/6 mice, the tumors shrank and disappeared by approximately 3 to 4 weeks.

One of these cell lines, termed JC1, was selected for further research as it exhibited better proliferative and migratory ability than the other cell lines (data not shown). To enhance the tumorigenicity of the $\mathrm{JC} 1$ cells, chemical induction was performed with the use of 4-NQO. The induced cells were then inoculated into immunocompetent C57BL/6 mice and tumors that grew stably in the immunocompetent mice were selected. The tumorigenic cell line with the optimal proliferative and migratory ability, JC1-2, was established for further research (Fig. S1B). The doubling time of the JC1-2 cells was $14.6 \mathrm{~h}$ (data not shown). The distribution of the cell cycle was also detected (Fig. S1C).

Immunogenomic and transcriptomic characterization of $\mathrm{JCl}$ and JC1-2 cells. To better understand the molecular basis of the differences in tumorigenicity between the JC1 and JC1-2 cell lines, whole-exome sequencing and single nucleotide polymorphism (SNP) array analysis were performed. Copy number variations, $\mathrm{LOH}$, somatic mutation single-nucleotide variants (SNVs) and insertions and deletions (indels) were identified. The 2 cell lines exhibited mostly diploid genomes, with some regions of amplifications and deletions (Fig. 1A). A total of 5,871 somatic mutations were identified in the JC1-2 
A
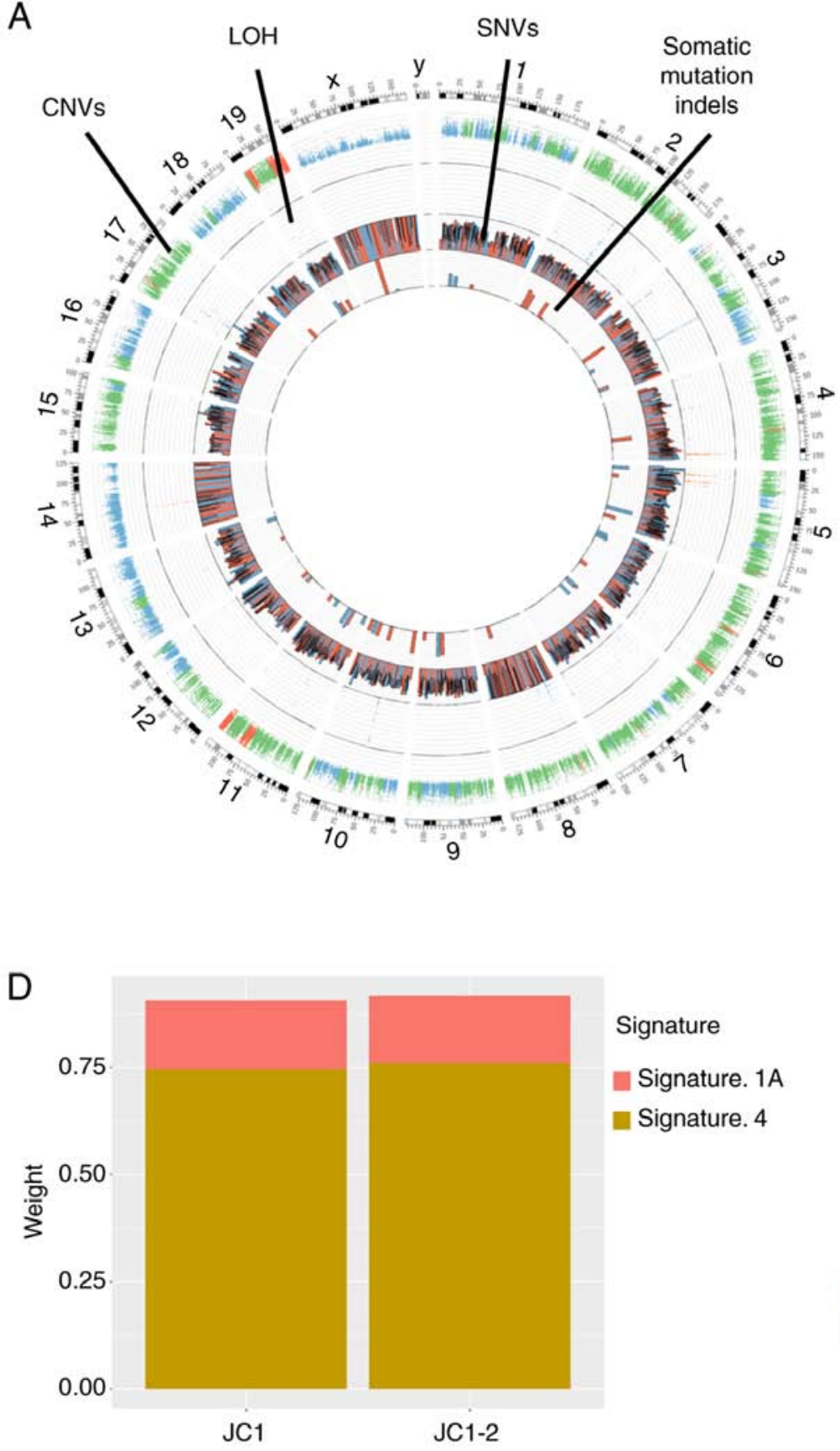

B

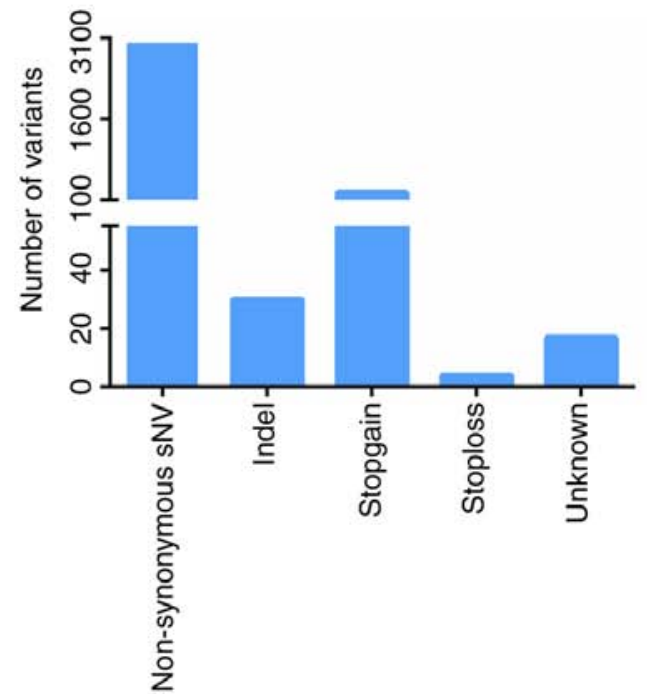

C
Number

669

74

E

$\mathrm{C}>\mathrm{A} / \mathrm{G}>\mathrm{T}$

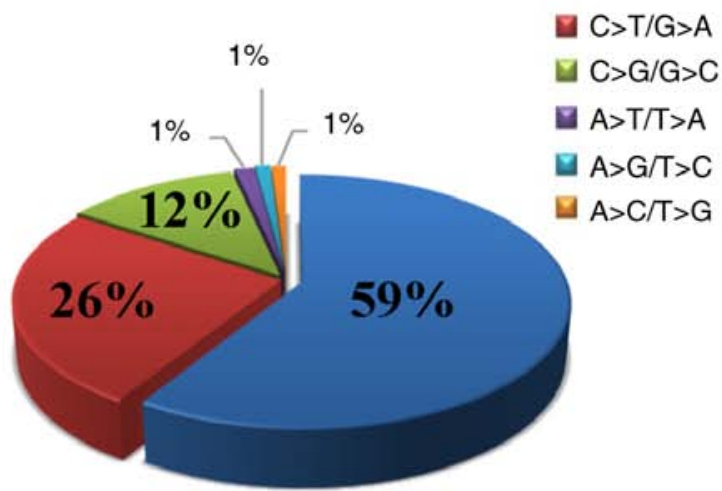

Figure 1. Immunogenomic and transcriptomic characterization of JC1 and JC1-2 cells. (A) Circos plot for JC1-2 cells; the tracks are numbered from the outside to the inside as follows: Track 1, genomic karyotypes (chromosomes and their corresponding numbers); track 2, somatic copy number variations (CNVs) of tumor cells; track 3, loss of heterozygosity (LOH); track 4, single nucleotide variants (SNVs) among tumor somatic mutations; track 5, indels among somatic mutations. In tracks 4 and 5, each column represents a mutation. Red represents functional mutations, including stop-gain, non-synonymous and frameshift mutations. Blue represents non-functional mutations. The frequency of mutations is represented by the height of each column. (B) Numbers of mutations in JC1-2 cells classified by type. (C) Numbers of predicted and expressed neoantigens in JC1-2 cells. (D) Contributions of published mutational signatures for JC1 and JC1-2 cells. The primary signature was Signature 4. (E) Six categories of base substitutions in JC1-2 cells.

cell line, of which 3,010 were non-synonymous and 30 were indels (Fig. 1B).

Tumor neoantigens originate from tumor-specific DNA alterations, do not exist in the normal genome, and can be presented and recognized by $\mathrm{T}$ lymphocytes. Identified potential neoantigens can be used to create synthetic vaccines and induce or expand neoantigen-specific $\mathrm{T}$ cells for combination with adjuvant and checkpoint blockade therapy (20). Therefore, in the present study, the numbers of predicted and expressed neoantigens were identified, which allowed us to better understand the immunogenicity of the JC1-2 cells. In the JC1-2 cells, 669 neoantigens were predicted to strongly bind to the C57BL/6 Mhc I molecules, $\mathrm{H} 2-\mathrm{Kb}$ and $\mathrm{H} 2-\mathrm{Db}$, at $<500 \mathrm{nM}$, and of these, 74 were expressed (Fig. 1C).

A previously published mutational signature classification system $(21,22)$ was used to identify the JC1-2 cell line. As shown by the results, JC1-2 was most similar to Signature 1A and Signature 4 (Fig. 1D). One mutational characterization of 
Signature 4 [which is exhibited in $35 \%$ of HNSCC cases (22)] is a high ratio of $\mathrm{C}>\mathrm{A} / \mathrm{G}>\mathrm{T}$ transversions $(21,22)$. In addition, a high frequency of $\mathrm{C}>\mathrm{A} / \mathrm{G}>\mathrm{T}$ transversions is considered to be a mutagen fingerprint of tobacco smoking $(23,24)$. The transversions were analyzed in the JC1-2 cells, and the majority of the transversions were $\mathrm{C}>\mathrm{A} / \mathrm{G}>\mathrm{T}(59 \%)$ (Fig. 1E). This may be since the JC1-2 cells originated from tumors induced by the chemical mutagen, 4-NQO. As a result, the JC1-2 cells exhibited similarities with patients HNSCC who are smokers, which accounts for the vast majority of patients with HNSCC, and may be a preclinical model for this group of patients.

The JC1 and JC1-2 cell lines exhibited clear distinctions (Fig. 2A). A gene-action-network was established for the key genes that were suggested to be significant by GO analysis. The most significantly differentially expressed genes were selected, and a protein-protein interaction (PPI) network between the JC1 and JC1-2 cells was established (Fig. 2B). In the network, genes related to antigen processing and presentation (B2m) and $\mathrm{H} 2-\mathrm{K} 1$, fibrinogen encoding (Fga, $\mathrm{Fgb}$ and $\mathrm{Fgg}$ ), fat transportation (Apoa1 and Apoa2) and the regulation of blood plasma colloid osmotic pressure (Alb) were found at central positions; these findings matched well with the significantly enriched pathways and functions of the differentially expressed genes classified by GO and KEGG analyses, which were associated with the immune system and metabolic processes (Fig. 2C and D). In addition, the observed lower expression levels of $\mathrm{B} 2 \mathrm{~m}$ and $\mathrm{H} 2-\mathrm{K} 1$ in the $\mathrm{JC} 1$ cells (Fig. S1D) suggested that the enhanced tumorigenicity of the JC1-2 cells may be due to reasons other than defects in the antigen processing machinery (APM) system.

Several markers have been reported to be predictive of the effectiveness of immune checkpoint inhibitor (ICI) therapy, such as MSI, PD-L1 expression and tumor mutation burden (TMB). It has been reported that patients with MSI-exhibiting colorectal cancer (CRC) have better prognoses and a longer survival time than those with MSS-exhibiting CRC (25-27). The mismatch repair (MMR) system is a security system that can repair DNA base mismatches. It plays roles in the restoration of normal nucleotide sequences in DNA molecules containing mismatched bases and can recognize and direct the repair of nucleotide mismatches derived from DNA polymerase errors. If the MMR system does not operate normally, mutations accumulate, which results in the pathogenesis and progression of some familial and sporadic cancers. Functional defects in the MMR system often lead to MSI (28). The present study analyzed mutations of 4 MMR genes in the JC1-2 cells: MLH1, MSH2, MSH6 and PMS2 (Fig. 2E). Only an MSH2 E455X nonsense mutation was found. Thus, the characterization of the genomic and transcriptomic landscapes of the HNSCC cell lines, JC1 and JC1-2, demonstrated that the JC1-2 cell line is a model cell line for MSS-exhibiting or MMR-proficient (pMMR) HNSCC.

The responsive IFN- $\gamma$ pathway in the JC1-2 cell line render it a serviceable model for tumor immunology. It is well accepted that the immune system plays an important role in tumor progression. Due to the differences in tumor formation rates between nude and C57BL/6 mice (data not shown), it was hypothesized that the immune system may play an important role in JC1-2 cell-derived transplanted tumor progression. $\mathrm{CD}^{+} \mathrm{T}$ cells cannot recognize tumor antigens to perform specific cell killing unless the APM system is functional. The IFN- $\gamma$ pathway of tumor cells is indispensable for the antitumor function of immune cells (29). To determine whether the IFN- $\gamma$ pathway is responsive to IFN- $\gamma$ in the JC1-2 cells, the IFN- $\gamma$-treated cells were compared to co-cultured cells. The results revealed that the levels of Mhc-I and PD-L1 were elevated to similar degrees in the IFN- $\gamma$-treated cells and splenocyte co-culture cells as in the control group, which indicated that the JC1-2 cells were responsive to IFN- $\gamma$. The inserts groups (Fig. 3A) did not differ as significantly as the above 2 groups, which indicated that direct contact was necessary for tumor antigen recognition (Fig. 3B-F).

To further identify the effects of different subgroups of immune cells on tumor cells, flow cytometry was performed to observe the changes in the expression of Mhc-I and PD-L1 in JC1-2 cells following co-culture. The results revealed that Mhc-I and PD-L1 expression in the cells co-cultured with total splenocytes was significantly higher than that in the control cells; Mhc-I and PD-L1 expression in the cells co-cultured with non- $\mathrm{CD}^{+}$cells was also higher than that in the control cells, while that in cells co-cultured with $\mathrm{CD}^{+} \mathrm{T}$ cells was not (Fig. 4A-C). The results of RT-qPCR were in accordance with these findings (Fig. 4D and E), which indicated that non-CD3 ${ }^{+}$ cells in splenocytes play an important role in the expression of PD-L1 and Mhc-I in JC1-2 cells.

Epidermal growth factor receptor (EGFR) is overexpressed in up to $90 \%$ of HNSCC cases and has been proven to be an effective target for HNSCC therapeutic strategies. EGFR is crucial to squamous cells and to signaling through the Ras-MAPK, PI3K-PTEN-AKT and phospholipase C pathways (30). The present study found that EGFR expression in cells co-cultured with total splenocytes also differed notably from that in the control group (Fig. S1E and F).

Comparison of the tumor immune microenvironment between the orthotopic and heterotopic models using multiplex fluorescent IHC. Multiplex fluorescent IHC was used to assess the landscape of the JC1-2 tumor immune microenvironment. Compared with other widely used syngeneic model tumors, such as B16, CT26, 4T1 and SCC7 transplanted tumors, the JC1-2-formed tumors exhibited a greater number of $\mathrm{CD}^{+} \mathrm{T}$ lymphocytes in the tumor microenvironment, most of which were $\mathrm{CD} 8^{+}$cytotoxic cells (Fig. 5).

Both orthotopic and heterotopic models were established, and the tumor samples were stained for CD3, CD8 and PD-1. Of note, there were distinct differences between tumors from the subcutaneous and buccal mucosae (Fig. 6A-N). A greater amount of $\mathrm{CD}^{+} \mathrm{T}$ cells existed in the orthotopic buccal tumors than in the heterotopic subcutaneous tumors, indicating that the immune responses were more intense in orthotopic model. $\mathrm{PD}-1^{+} \mathrm{CD}^{+}$tumor-infiltrating lymphocytes (TILs) are considered to form the basis of PD-1/PD-L1 immunotherapy $(31,32)$. In the present study, the amount of $\mathrm{CD}^{+}$and $\mathrm{CD} 8^{+} \mathrm{TILs}$ in the orthotopic tumors was greater than that in the heterotopic tumors, which indicated that the orthotopic tumor model was a better selection for immunotherapy evaluation. Additionally, a higher B2m expression was found in the orthotopic model than in the heterotopic model (Fig. $6 \mathrm{O}$ and $\mathrm{P}$ ) and the majority of B2m-positive cells, were immune cells, which verified that 
A

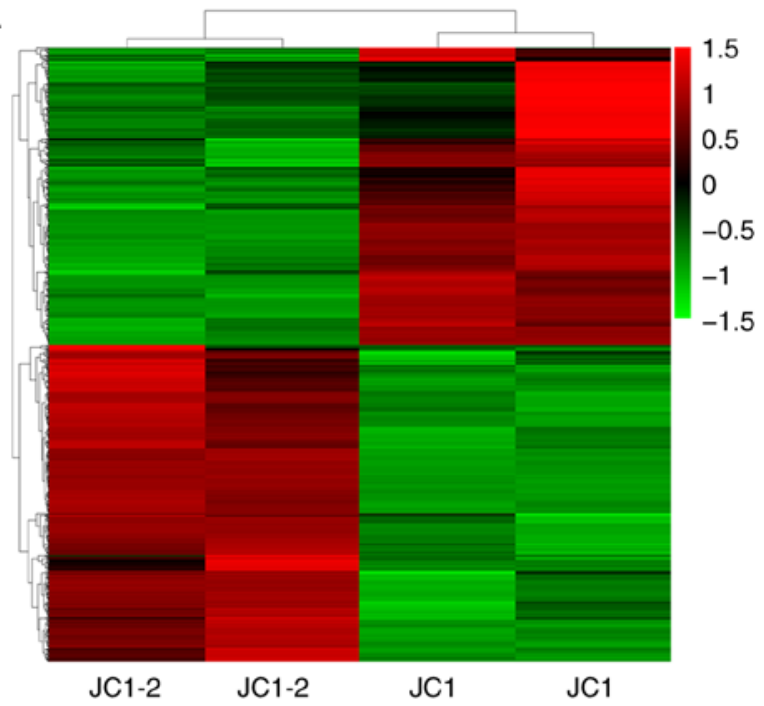

B

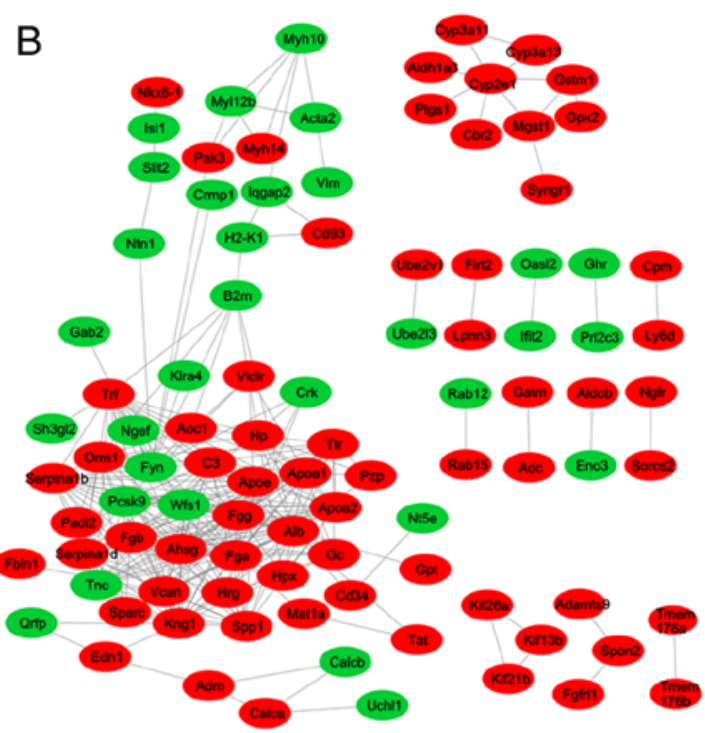

GO_domain

$\mathrm{D}$

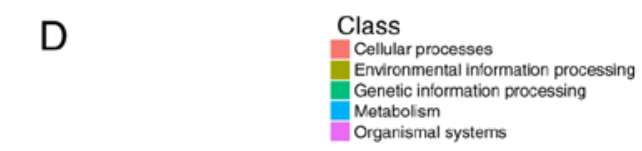

Biological_process

Molecular_function

GO classification

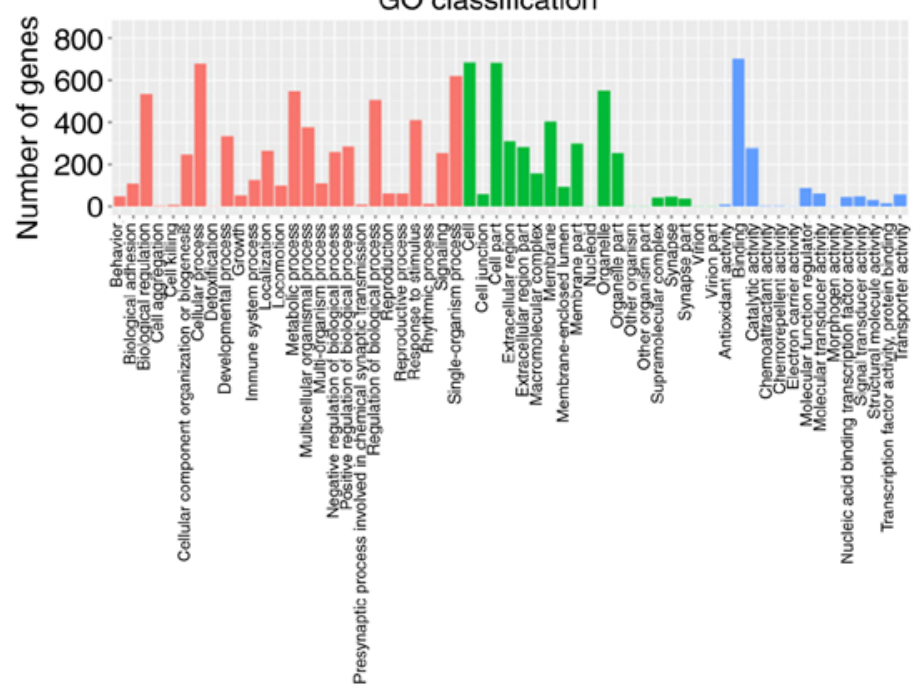

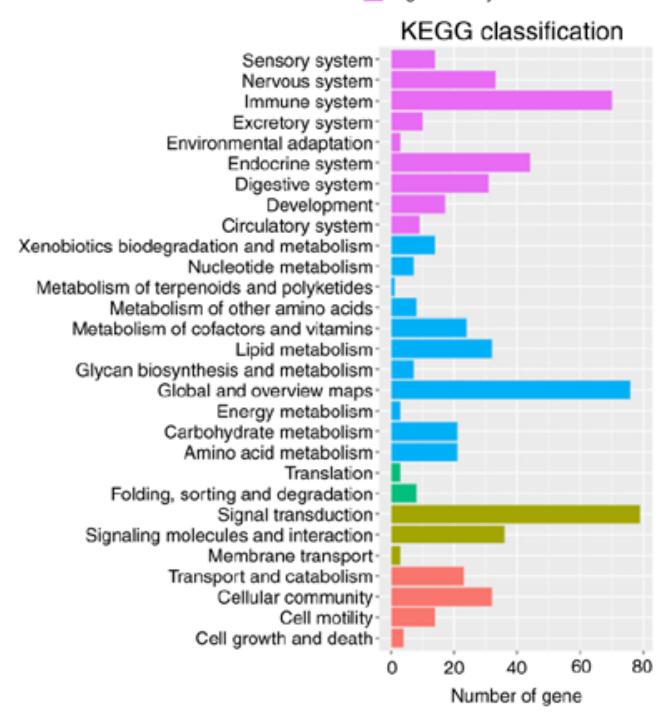

E
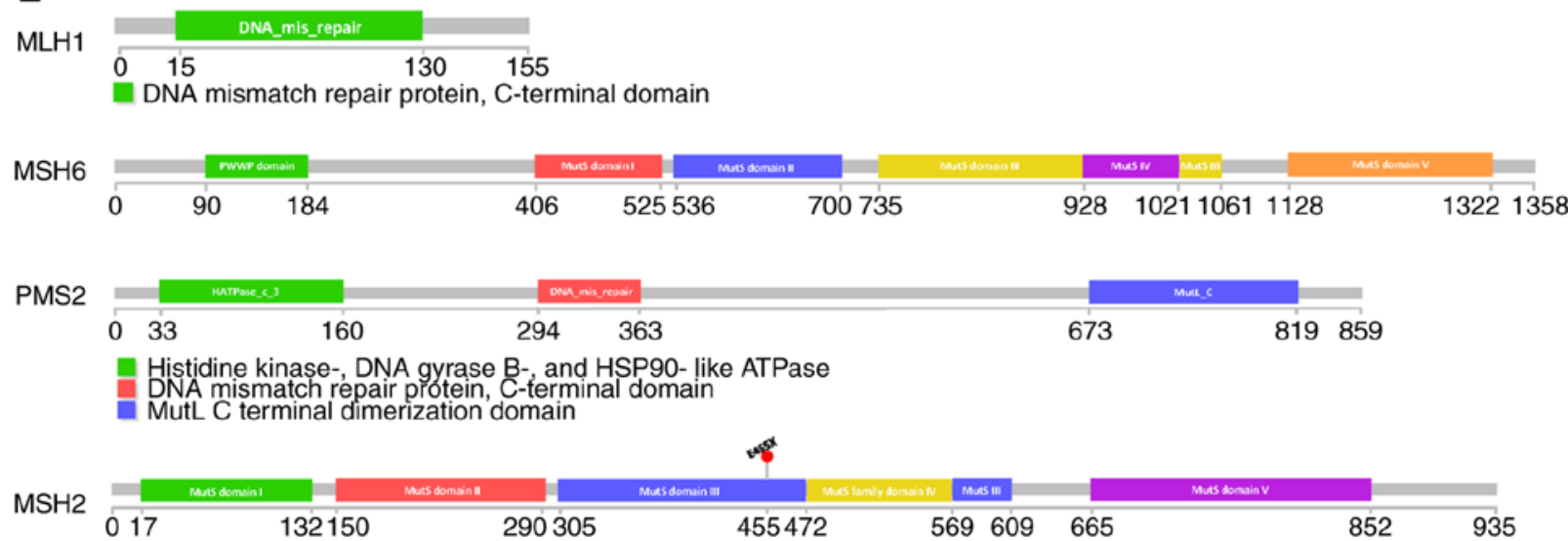

Figure 2. Differential gene expression analysis, function and pathway enrichment analysis and microsatellite analysis of the JC1-2 cell line. (A) Heatmap of differentially expressed genes between the cell lines, JC1 and JC1-2. (B) Protein-protein interaction (PPI) network of JC1 compared with JC1-2 cells. (C and D) Gene Ontology (GO) (C) and Kyoto Encyclopedia of Genes and Genomes (KEGG). (D) Function and pathway enrichment for the significantly differentially expressed genes between JC1 and JC1-2 cells. (E) Gene diagrams for the functional domains and protein modifications of the MMR genes MLH1, MSH2, MSH6 and PMS2 in JC1-2 cells. 


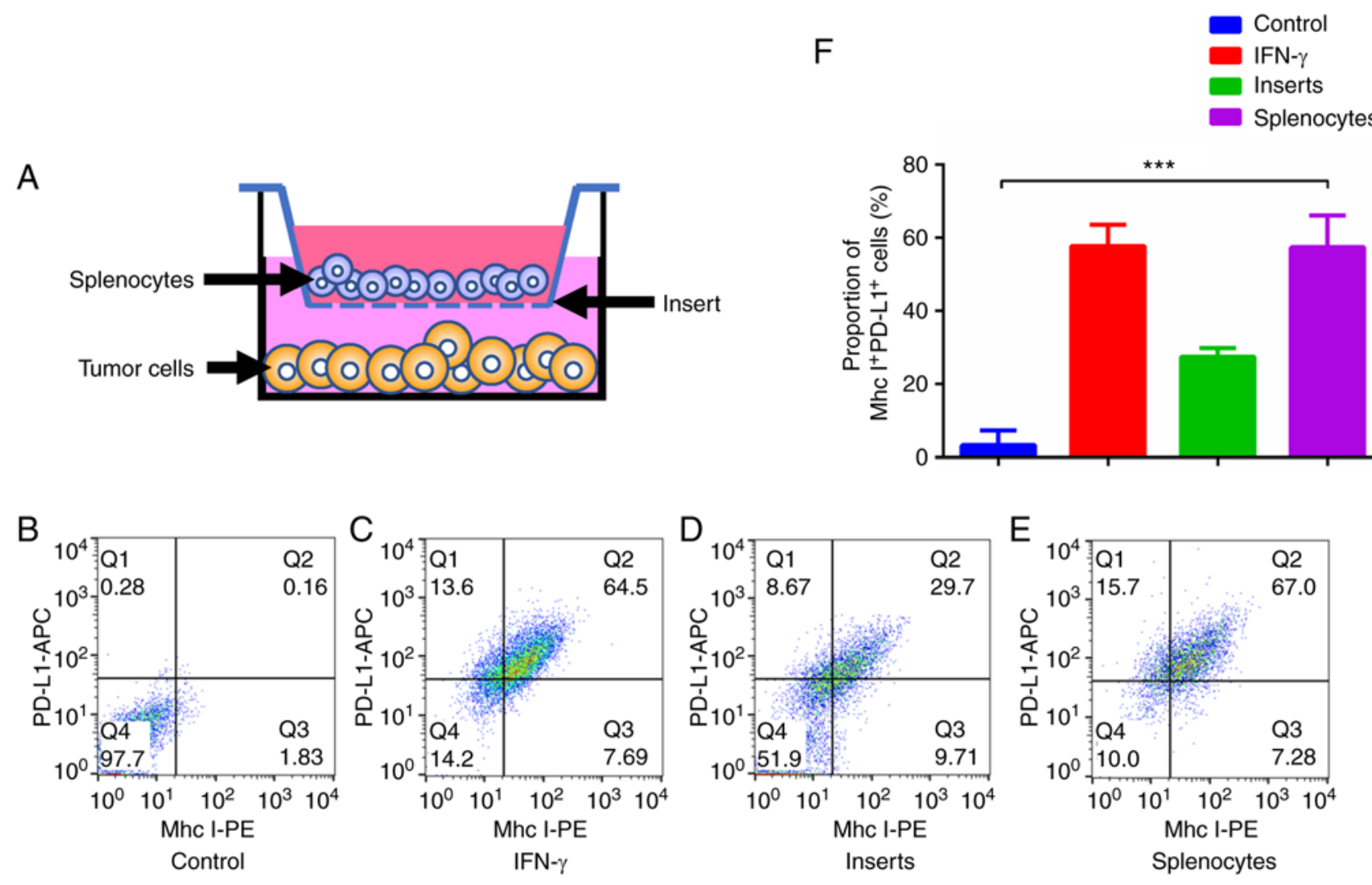

Figure 3. Expression of Mhc I and PD-L1 in JC1-2 cells subjected to different treatments. (A) Schematic diagram of the use of Millicell Hanging Cell Culture Inserts. (B-E) Expression of Mhc I and PD-L1, as assessed by flow cytometry in differently treated JC1-2 cells and (F) proportion of Mhc I and PD-L1 double-positive cells in co-cultured JC1-2 cells $(\mathrm{n}=3)$. Bars represent the means \pm SD. ${ }^{* * *} \mathrm{P}<0.001$.

the immune response was more intense in the orthotopic model.

Through multiplex fluorescent IHC and H\&E staining, the immune microenvironments of HNSCC tumors were examined. The imaging results revealed that the tumors formed from JC1-2 cells were 'inflamed tumors' with abundant immune-subset cells within the intratumoral and peritumoral microenvironment. Such findings are rare in current experimental tumor models and indicate that this model may be a useful tool for further studies on immunotherapy. It could be used as an experimental model for screening or development of anticancer drugs and for verification of related molecular mechanisms. With the help of multiplex IHC, the JC1-2 tumor model may be used as a reliable platform that exhibits an intratumoral immune microenvironment appropriate for further immunotherapy research on HNSCC patients who are smokers.

\section{Discussion}

Mice are often used as animal models to examine the tumor microenvironment and to verify the related molecular mechanisms in order to enhance our understanding of the occurrence and progression of HNSCC and for the development of therapeutic strategies (33). A crucial aspect of a preclinical model is that it mimics human cancer development. Due to its time-consuming and unrepeatable natures of the current models, we performed primary culture to establish an HNSCC cell line model. The resulting syngeneic murine tumor model is fully immune-competent and will be particularly useful in the evaluation of immuno-oncology agents, as it can be used to study the generation of antitumor immune responses and does not require the adoptive transfer of immune populations. Additionally, this cell line model is more reliable than existing models due to its repeatability and easy operation.

In the present study, the originally established cell line JC1 was cultured in vitro and subjected to repeated passaging and monoclonal screening. Under such conditions, alterations in some biological and genetic characteristics (such as immunogenicity) can occur in this cell line. As a result, the JC1 cells exhibited tumorigenicity in immunodeficient nude mice, but could not grow into tumors in immunocompetent C57BL/6 mice (data not shown). In addition, it has been reported that in chronic infections and cancer, $\mathrm{T}$ cells tend to become non-functional (at which point they are termed exhausted T cells) and express several inhibitory receptors because of persistent exposure to antigens (34). In the present study, compared to transplanted tumors, the 4-NQO-induced tumors exhibited a more immunosuppressive microenvironment, which may explain why the JC1 cells can only grow into tumors in nude mice. Fortunately, the JC1-2 cell line established through chemical induction exhibited tumorigenicity in immunocompetent C57BL/6 mice.

Through NGS, it was found that the HNSCC cell lines that was established herein may be of great value as alternatives in clinical trials for a specific group of patients. It was verified that both JC1 and JC1-2 cells exhibited MSS phenotype. Notably, HNSCC cell lines with MSI have been reported to 

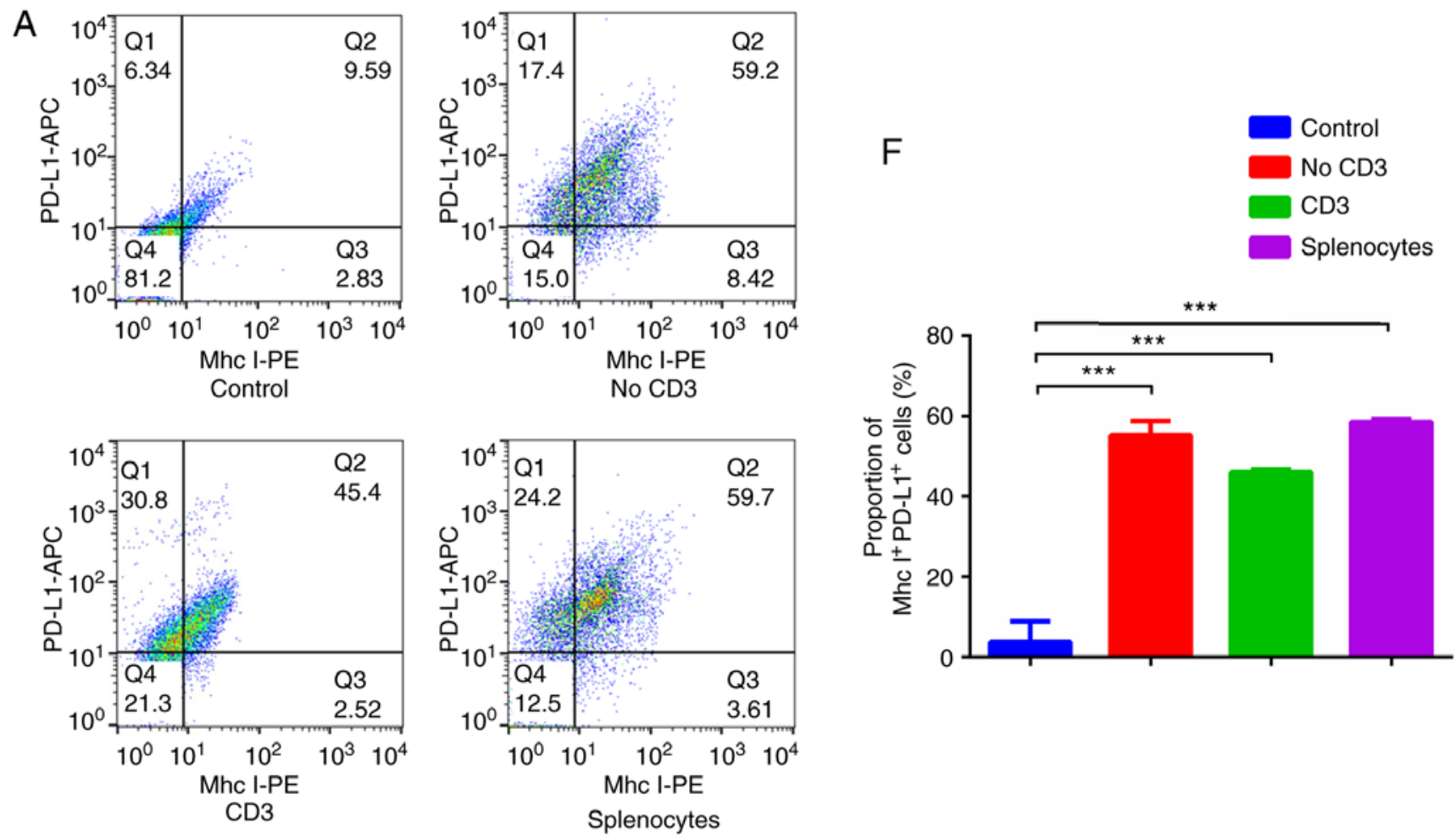

C

D
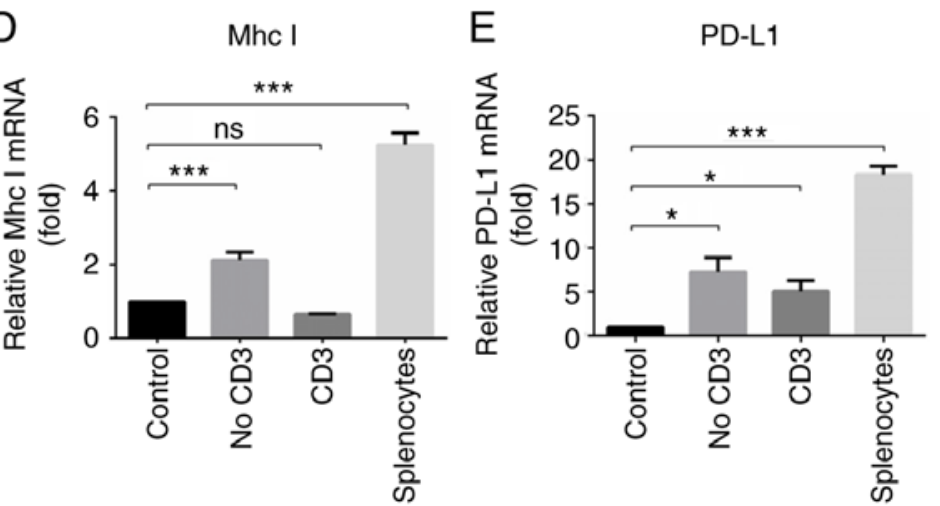

Figure 4. Expression of Mhe I and PD-L1 in the JC1-2 cell line following co-culture with different types of splenocytes. (A) Expression of Mhe I and PD-L1, as assessed by flow cytometry in differently treated JC1-2 cells. (B and C) Histograms of Mhe I and PD-L1 in co-cultured JC1-2 cells. (D and E) mRNA expression of Mhc I in co-cultured JC1-2 cells. (F) Proportion of Mhc I and PD-L1 double-positive cells in co-cultured JC1-2 cells ( $\mathrm{n}=3$ ). Bars represent the means \pm SD. ns, not significant $(\mathrm{P}>0.05) ;{ }^{*} \mathrm{P}<0.05 ;{ }^{* * * *} \mathrm{P}<0.001$.

exhibit decreased sensitivity to chemotherapeutic drugs. $\mathrm{LOH}$ is a common mechanism of inactivation of tumor-suppressor genes, which might be related to chemotherapy resistance. Further sequencing and analysis of the genome or the gene expression patterns of JC1-2 cells or transplanted tumors could reveal matched clinical patient subgroups whose tumors may have similar biological behaviors and key gene mutations. Hence, this mouse model, and this approach of model establishment, could be of great significance for early diagnosis of HNSCC, direction of therapeutic strategies and prediction of the antitumor efficacy of immunotherapy.

Differences between JC1 and JC1-2 cells in CNVs, somatic number variations, $\mathrm{LOH}$, base changes and substitutions, enriched functions and pathways for significantly differentially expressed genes and protein-protein interactions were revealed by the present findings. However, further bioinformatics analyses are warranted to explore the potential factors affecting the tumorigenicity of these tumor cells. In particular, the most significantly differentially expressed genes should be investigated as they could be potential therapeutic targets for HNSCC.

By comparing JC1-2 cells cultured alone and co-cultured with different subgroups of splenocytes, it was confirmed that the gene expression of tumor cells can be significantly altered through coculture with immune cells in vitro. Non-CD3 ${ }^{+}$cells include several subgroups of immune cells, such as dendritic cells (DCs), macrophages and natural killer (NK) cells, which play significant roles in antigen processing and, antigen presentation and exhibit strong killing effects on tumor cells. The results suggest that non-CD3 ${ }^{+}$cells are important components in the interactions between tumor cells and the immune system. The killing effects of $\mathrm{CD}^{+}$cells towards tumor cells are based on the proper functioning of the Mhc I APM. Mhc peptide complexes can be recognized by $\mathrm{T}$ cell receptors (TCRs), thus 
A

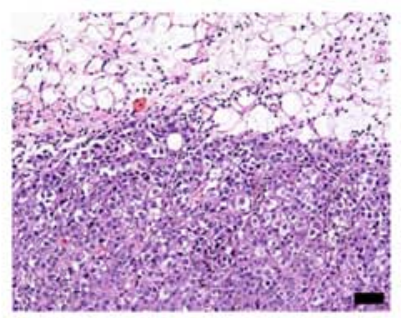

C
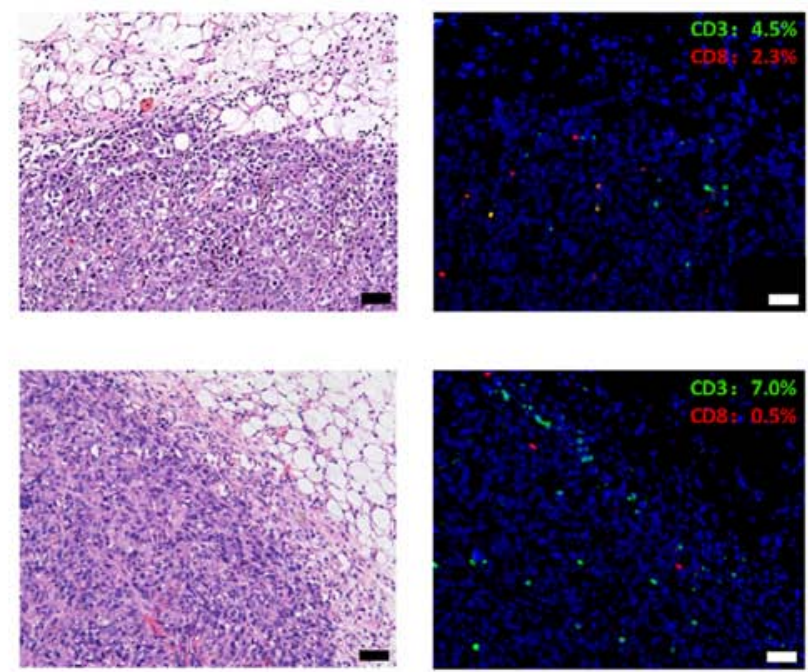

B
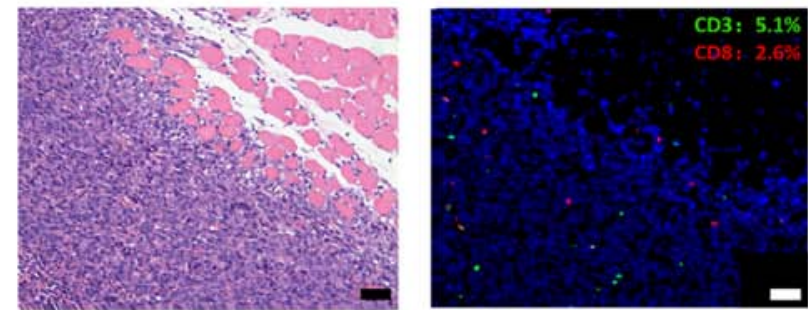

D

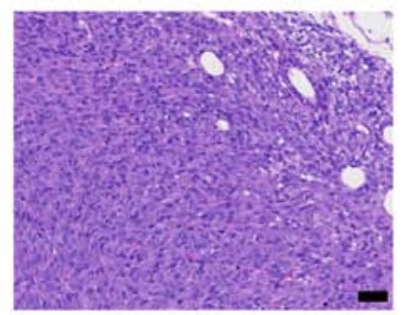

$\mathrm{F}$
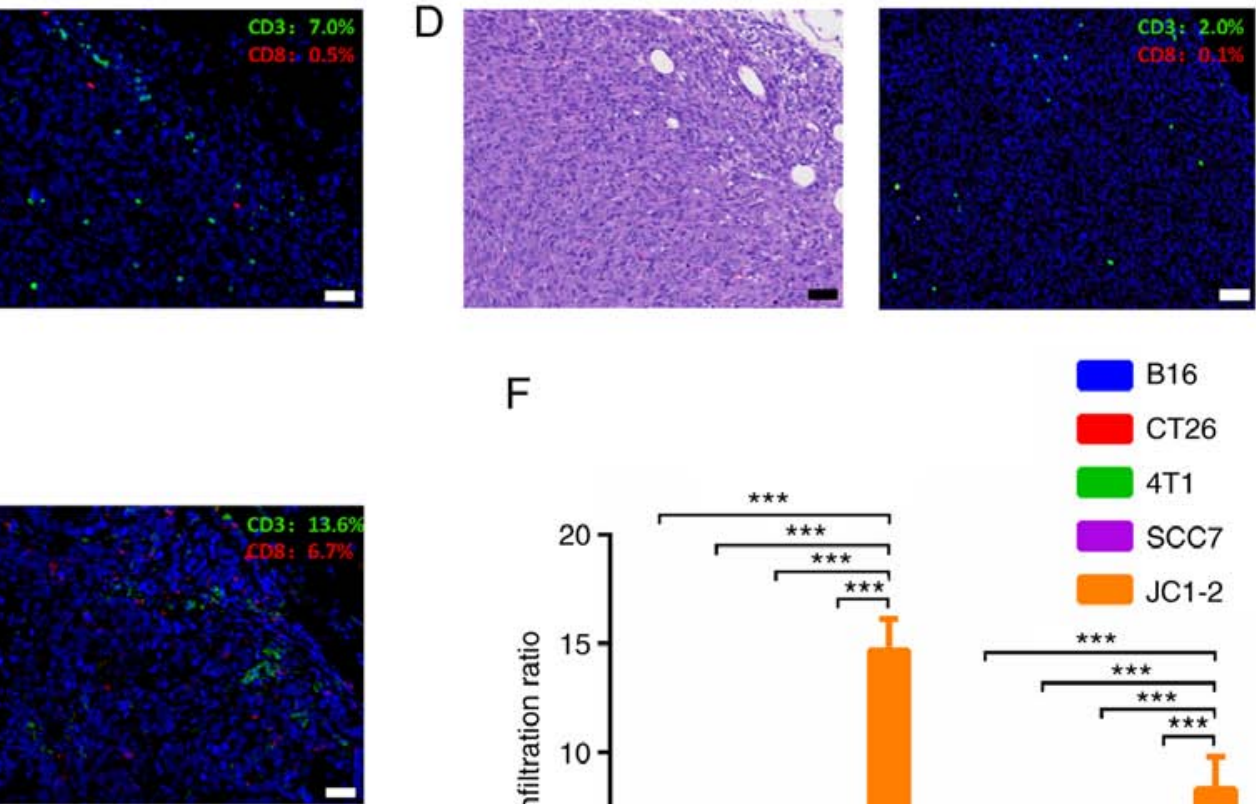

$\mathrm{E}$

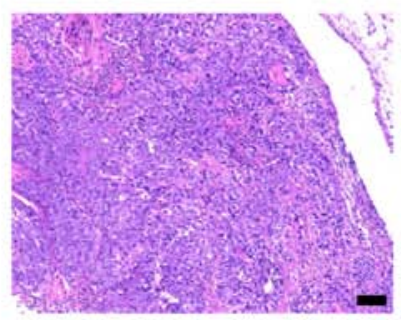

(⿸\zh14口)

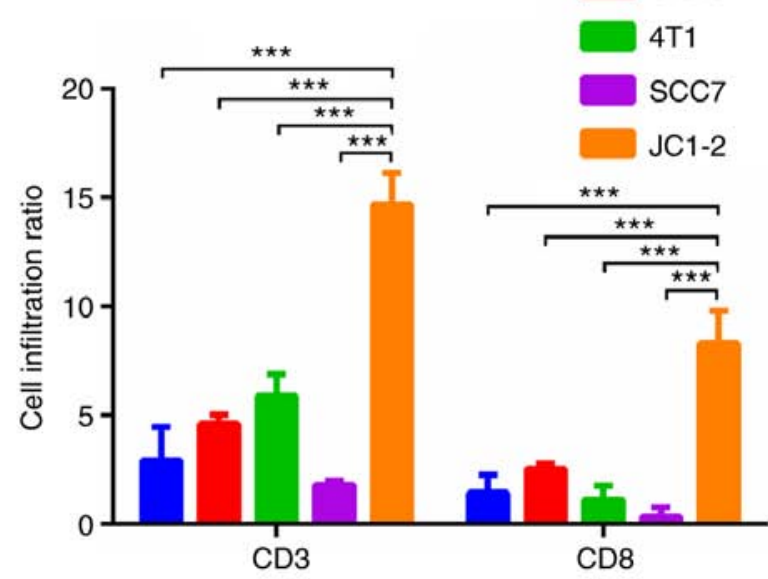

Figure 5. Expression levels of T lymphocytes for different types of tumors. (A) Representative H\&E and immunofluorescence staining of B16 cell-derived tumors. (B) Representative H\&E and immunofluorescence staining of CT26 cell-derived tumors. (C) Representative H\&E and immunofluorescence staining of $4 \mathrm{~T} 1$ cell-derived tumors. (D) Representative H\&E and immunofluorescence staining of SCC7 cell-derived tumors. (E) Representative H\&E and immunofluorescence staining of JC1-2 cell-derived tumors. (F) Cell infiltration ratio of different types of tumors. Green, CD3; red, CD8. Scale bar, $50 \mu \mathrm{m}(\mathrm{n}=3)$. ${ }^{* * * *} \mathrm{P}<0.001$.

leading to TCR activation and tumor-killing effects. An intact Mhc I APM is indispensable for immunocytes responses to tumors. The expression levels of Mhc I in untreated JC1 and JC1-2 cells were low (Fig. S1D); however, Mhc expression was increased on JC1-2 cells stimulated with IFN- $\gamma$ and splenocytes, indicating that experiments in vitro may not reflect the real interactions between immune cells and tumor cells. Thus, in vivo tumor models were deemed necessary. $\mathrm{B} 2 \mathrm{~m}$ was identified to stabilize the synthesized Mhe I- peptide complex so that it could be expressed on the cell surface. IT was found that $\mathrm{H} 2-\mathrm{K} 1$ and $\mathrm{H} 2-\mathrm{D} 1$ expression was even higher in the $\mathrm{JC1}-2$ cells than in the JC1 cells, which suggested that enhanced immunogenicity and tumorigenicity of JC1-2 cells may be due to some reasons except the defect of the antigen processing machinery (APM) system. In the present study, clear differences in B2m expression were revealed between orthotopic and heterotopic tumor models. Further studies should focus on the immune escape mechanism. Generally, the JC1-2 cell line had a responsive IFN- $\gamma$ pathway and thus may potentially be suitable for drug screening and immunotherapy evaluation in vitro. In addition, the JC1-2 cell line may also be an appropriate model for exploration of the mechanisms of interactions between tumor cells and immune cells in vitro.

The $\mathrm{CD}^{+} \mathrm{T}$ effector cell population is believed to be a major immune cell population in antitumor adaptive immunity and to represent a significant independent prognostic factor (35), but other types of cells, such as macrophages, DCs and B cells, are also indispensable for effective presentation, recognition and tumor killing. Under normal conditions, the immune system reacts to exogenous antigens that carry danger signals, leading to the proliferation of antigen-specific $\mathrm{CD}^{+}$ $\mathrm{T}$ cells and/or $\mathrm{CD} 4^{+}$helper cells. As a result, the proliferation of antigen-specific $\mathrm{T}$ cells and the apoptosis of regulatory $\mathrm{T}$ cells are markedly reduced, and thus, suppress tumor growth $(36,37)$. Upon IFN- $\gamma$ stimulation, PD-L1 is expressed on T cells and other immune cells (38). It was hypothesized that tumor antigens cannot be recognized and presented normally without the APM; thus, the progression of malignancy is greatly influenced by whether an integrated immune system exists. The transplantation of tumors into immunodeficient nude mice 

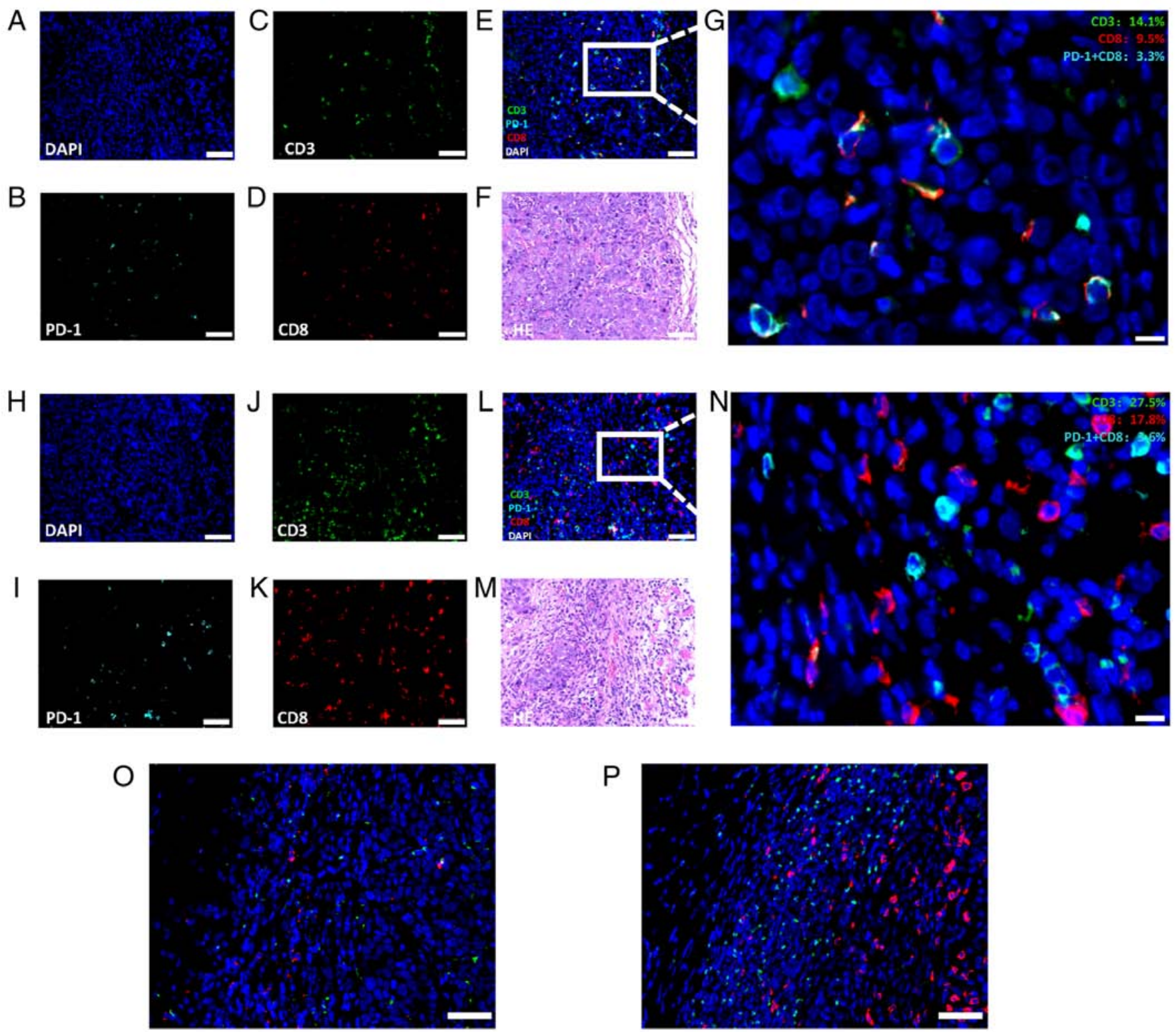

Figure 6. Expression levels of immune cell subsets in (A-G) heterotopic and (H-N) orthotopic tumor models. (A and H) Representative immunofluorescence staining with DAPI (blue). (B and I) Representative immunofluorescence staining of PD-1 (cyan). (C and J) Representative immunofluorescence staining of CD3 (green). (D and K) Representative immunofluorescence staining of CD8 (red). (E, G, L and N) Representative multiplex fluorescent immunohistochemical staining images. (G and N) Enlarged images of the area in the white boxes in (E and L). (F and M) Representative H\&E staining. (O) Representative immunofluorescence images of JC1-2 heterotopic tumors. (P) Representative immunofluorescence images of JC1-2 orthotopic tumors. Green, CD8; red, B2m. (A-F, H-M, and $\mathrm{O}$ and P) Scale bar, $50 \mu \mathrm{m}$; (G and N) scale bar, $10 \mu \mathrm{m}(\mathrm{n}=3)$.

may therefore not be an appropriate method for tumor immunology research. Tumors transplanted into immunocompetent mice better reflect the biological behaviors and genetic characteristics of tumors in humans than those transplanted into immunodeficient mice. In addition, it is important to explore the functionality of different subgroups of immune cells. In the present study, some functional immune cells were identified, such as CD8 ${ }^{+} \mathrm{PD}-1^{+}$cytotoxic T cells (CTLs). The present study however, did not analyze the functional and spatial characteristics of these cells in detail; such an analysis may provide additional information for studies on immunotherapy and the tumor microenvironment that will enable the enhanced understanding of the progression of malignancy. Combined with multiplex IHC, this cell line model can also be a useful tool for potential immunotherapy target screening, pharmacodynamic evaluation, and the investigation of the immune microenvironment of HNSCC. JC1-2 cells provide a more reliable preclinical model than existing models for biomarker investigation, drugs targeting screening and immunotherapy optimization.

Tumor heterogeneity has long been one of the most significant reasons for tumor metastasis, recurrence and drug resistance (39). IHC is an important auxiliary method for clinical pathologic diagnosis. Since a number of immunotherapies can benefit from biomarkers, techniques such as multiplex IHC, which enables clear visualization of multiple markers on a single slide, have been widely utilized. Multiplex IHC on human tumor tissues has been carried out for a long time and its process has been continuously optimized $(40,41)$. However, similar methods have rarely been carried out on murine tumor tissues as epitopes, such as CD4 and CD8 were not to 
be sufficiently detected in formalin-fixed paraffin-embedded (FFPE) samples until recently (42). Therefore, flow cytometry has long been the gold standard for the analysis of TILs in the tumor microenvironment (43). However, flow cytometry cannot provide exact dimensional information, which has been proven to be significant in the diagnosis and prognosis of malignancies. Multiplex IHC provides more quantitative and spatial information on the tumor microenvironment than flow cytometry and is of great value for multitarget combination therapy.

Notably, the formation rate of JC1-2 transplanted tumors in immunocompetent mice was not $100 \%$ and the growth rates of the tumors were relatively slower than those of tumors in widely used syngeneic models, such as B16 and SCC7 models; these findings indicate that $\mathrm{JC} 1-2$ cells may have relatively high immunogenicity. Different syngeneic mice exhibited different degrees of tumorigenicity (immune responses) upon JC1-2 inoculation, which resembles the clinical situation in which individuals exhibit different responses to the same therapeutic regimen. The JC1-2 cell line model may be an excellent tool for the observation of early-stage HNSCC (particularly as regards 'inflamed' tumors, which severely lack preclinical models) and an appropriate model for studying the tumorigenesis and progression of HNSCC. The abundant PD- $1^{+} \mathrm{T}$ cells in the tumor microenvironments of JC1-2 transplanted tumors suggest that the JC1-2 tumor model may have a positive response to PD-1/PD-L1 blockade. Further research evaluating drug safety and efficacy is required to verify the previous results in vitro, and target screening and pharmacodynamic evaluation is also warranted.

The syngeneic murine tumor model established in the present study has the ease of use, since JC1-2 cells can be rapidly and reproducibly expanded in large numbers. It can also be used for research on the impacts of immune cells on tumor development and antitumor immune responses and for the evaluation of immunotherapies. This syngeneic murine tumor model may prove to be of great value for diagnosis and for the evaluation of novel immunotherapies.

\section{Acknowledgements}

Not applicable.

\section{Funding}

The present study was supported by The Ninth People's Hospital affiliated to the Shanghai Jiao Tong University School of Medicine supported by the National Natural Science Foundation of China (grant no. 81902749) and the China Postdoctoral Science Foundation (grant no. 2017M610264).

\section{Availability of data and materials}

All data generated or analyzed during this study are included in this published article or are available from the corresponding author on reasonable request.

\section{Authors' contributions}

YF and GT made substantial contributions to the conception and design of the study, as well as in the acquisition, analysis, or interpretation of data for the study. JL and ZZ made substantial contributions to the conception and design of the study and together with the other authors, gave the final approval of the version to be published and agreement to be accountable for all aspects of the work in ensuring that questions related to the accuracy or integrity of any part of the work are appropriately investigated and resolved. KX was involved in the drafting of the study or revising it critically for important intellectual content, as well as in the acquisition, analysis, or interpretation of data for the study. All authors have read and approved the final manuscript.

\section{Ethics approval and consent to participate}

All animal experiments were approved by and performed in accordance with the guidelines of the Shanghai Jiao Tong University School of Medicine.

\section{Patient consent for publication}

Not applicable.

\section{Competing interests}

The authors declare that they have no competing interests.

\section{References}

1. De Moerlooze L, Spencer-Dene B, Revest JM, Hajihosseini M, Rosewell I and Dickson C: An important role for the IIIb isoform of fibroblast growth factor receptor 2 (FGFR2) in mesenchymal-epithelial signalling during mouse organogenesis. Development 127: 483-492, 2000.

2. Kang H, Kiess A and Chung CH: Emerging biomarkers in head and neck cancer in the era of genomics. Nat Rev Clin Oncol 12: 11-26, 2015.

3. Bray F, Ferlay J, Soerjomataram I, Siegel RL, Torre LA and Jemal A: Global cancer statistics 2018: GLOBOCAN estimates of incidence and mortality worldwide for 36 cancers in 185 countries. CA Cancer J Clin 68: 394-424, 2018.

4. Beenken A and Mohammadi M: The FGF family: Biology, pathophysiology and therapy. Nat Rev Drug Discov 8: 235-253, 2009.

5. Rothschild U, Muller L, Lechner A, Schlösser HA, Beutner D, Läubli H,Zippelius A and Rothschild SI: Immunotherapy in head and neck cancer-scientific rationale, current treatment options and future directions. Swiss Med Wkly 148: w14625, 2018.

6. Gould SE, Junttila MR and de Sauvage FJ: Translational value of mouse models in oncology drug development. Nat Med 21: 431-439, 2015.

7. de Visscher SA, Witjes MJ, van der Vegt B, de Bruijn HS van der Ploeg-van den Heuvel A, Amelink A, Sterenborg HJ, Roodenburg JL and Robinson DJ: Localization of liposomal mTHPC formulations within normal epithelium, dysplastic tissue, and carcinoma of oral epithelium in the 4NQO-carcinogenesis rat model. Lasers Surg Med 45: 668-678, 2013.

8. Miki K, Orita Y, Gion Y, Takao S, Ohno K, Takeuchi M, Ito $\mathrm{T}$, Minoura $\mathrm{A}$, Tachibana $\mathrm{T}$, Marunaka $\mathrm{H}$, et al: Tumor-associated macrophages in the development of 4-nitroquinoline-1-oxide-induced tongue squamous cell carcinoma in a mouse model. Oncology 93: 204-212, 2017.

9. Young MR: Use of carcinogen-induced premalignant oral lesions in a dendritic cell-based vaccine to stimulate immune reactivity against both premalignant oral lesions and oral cancer. J Immunother 31: 148-156, 2008.

10. Tseng SH, Yang CC, Yu EH, Chang C, Lee YS, Liu CJ, Chang KW and Lin SC: K14-EGFP-miR-31 transgenic mice have high susceptibility to chemical-induced squamous cell tumorigenesis that is associating with $\mathrm{Ku} 80$ repression. Int J Cancer 136: 1263-1275, 2015. 
11. Miki K, Orita Y, Gion Y, Takao S, Ohno K, Takeuchi M, Ito T, Hanakawa H, Tachibana T, Marunaka H, et al: Regulatory $\mathrm{T}$ cells function at the early stage of tumor progression in a mouse model of tongue squamous cell carcinoma. Cancer Immunol Immunother 65: 1401-1410, 2016.

12. Yang Y: Cancer immunotherapy: Harnessing the immune system to battle cancer. J Clin Invest 125: 3335-3337, 2015.

13. Lu X, Horner JW, Paul E, Shang X, Troncoso P, Deng P, Jiang S, Chang Q, Spring DJ, Sharma P, et al: Effective combinatorial immunotherapy for castration-resistant prostate cancer. Nature 543: 728-732, 2017.

14. Olson B, Li Y, Lin Y, Liu ET and Patnaik A: Mouse models for cancer immunotherapy research. Cancer Discov 8: 1358-1365, 2018.

15. Efremova M, Rieder D, Klepsch V, Charoentong P, Finotello F Hackl H, Hermann-Kleiter N, Löwer M, Baier G, Krogsdam A and Trajanoski Z: Targeting immune checkpoints potentiates immunoediting and changes the dynamics of tumor evolution. Nat Commun 9: 32, 2018

16. Tang XH, Knudsen B, Bemis D, Tickoo S and Gudas LJ: Oral cavity and esophageal carcinogenesis modeled in carcinogen-treated mice. Clin Cancer Res 10: 301-313, 2004.

17. DePristo MA, Banks E, Poplin R, Garimella KV, Maguire JR, Hartl C, Philippakis AA, del Angel G, Rivas MA, Hanna M, et al: A framework for variation discovery and genotyping using next-generation DNA sequencing data. Nat Genet 43: 491-498, 2011.

18. McKenna A, Hanna M, Banks E, Sivachenko A, Cibulskis K, Kernytsky A, Garimella K, Altshuler D, Gabriel S, Daly M and DePristo MA: The Genome Analysis Toolkit: A MapReduce framework for analyzing next-generation DNA sequencing data. Genome Res 20: 1297-1303, 2010.

19. Livak KJ and Schmittgen TD: Analysis of relative gene expression data using real-time quantitative PCR and the 2(-Delta Delta C(T)) method. Methods 25: 402-408, 2001

20. Schumacher TN and Schreiber RD: Neoantigens in cancer immunotherapy. Science 348: 69-74, 2015.

21. Alexandrov LB, Nik-Zainal S, Wedge DC, Campbell PJ and Stratton MR: Deciphering signatures of mutational processes operative in human cancer. Cell Rep 3: 246-259, 2013.

22. Alexandrov LB, Nik-Zainal S, Wedge DC, Aparicio SA, Behjati S, Biankin AV, Bignell GR, Bolli N, Borg A, Børresen-Dale AL, et al: Signatures of mutational processes in human cancer. Nature 500: 415-421, 2013.

23. Sun S, Schiller JH and Gazdar AF: Lung cancer in never smokers-a different disease. Nat Rev Cancer 7: 778-790, 2007.

24. Le Calvez F, Mukeria A, Hunt JD, Kelm O, Hung RJ, Tanière $P$ Brennan P, Boffetta P, Zaridze DG and Hainaut P: TP53 and KRAS mutation load and types in lung cancers in relation to tobacco smoke: Distinct patterns in never, former, and current smokers. Cancer Res 65: 5076-5083, 2005.

25. Collura A, Lagrange A, Svrcek M, Marisa L, Buhard O, Guilloux A, Wanherdrick K, Dorard C, Taieb A, Saget A, et al: Patients with colorectal tumors with microsatellite instability and large deletions in HSP110 T17 have improved response to 5-fluorouracil-based chemotherapy. Gastroenterology 146: 401-411, 2014

26. Tajima A, Hess MT, Cabrera BL, Kolodner RD and Carethers JM: The mismatch repair complex hMutS alpha recognizes 5-fluorouracil-modified DNA: Implications for chemosensitivity and resistance. Gastroenterology 127: 1678-1684, 2004.

27. Hemminki A, Mecklin JP, Jarvinen H, Aaltonen LA and Joensuu H: Microsatellite instability is a favorable prognostic indicator in patients with colorectal cancer receiving chemotherapy. Gastroenterology 119: 921-928, 2000.
28. Baretti M and Le DT: DNA mismatch repair in cancer. Pharmaco Ther 189: 45-62, 2018.

29. Gao J, Shi LZ, Zhao H, Chen J, Xiong L, He Q, Chen T, Roszik J, Bernatchez C, Woodman SE, et al: Loss of IFN- $\gamma$ pathway genes in tumor cells as a mechanism of resistance to anti-CTLA-4 therapy. CELL 167: 397-404, 2016.

30. Hynes NE and Lane HA: ERBB receptors and cancer: The complexity of targeted inhibitors. Nat Rev Cancer 5: 341-354, 2005.

31. Mattox AK, Lee J, Westra WH, Pierce RH, Ghossein R, Faquin WC, Diefenbach TJ, Morris LG, Lin DT, Wirth LJ, et al: $\mathrm{PD}-1$ expression in head and neck squamous cell carcinomas derives primarily from functionally anergic CD4(+) TILs in the presence of PD-L1(+) TAMs. Cancer Res 77: 6365-6374, 2017.

32. Zhou G, Sprengers D, Boor PPC, Doukas M, Schutz H, Mancham S, Pedroza-Gonzalez A, Polak WG, de Jonge J, Gaspersz M, et al: Antibodies against immune checkpoint molecules restore functions of tumor-infiltrating T cells in hepatocellular carcinomas. Gastroenterology 153: 1107-1119, 2017.

33. Bi Y, Deng J, Murry DJ and An G: A whole-body physiologically based pharmacokinetic model of gefitinib in mice and scale-up to humans. AAPS J 18: 228-238, 2016.

34. Wherry EJ and Kurachi M: Molecular and cellular insights into T cell exhaustion. Nat Rev Immunol 15: 486-499, 2015.

35. Topalian SL, Taube JM, Anders RA and Pardoll DM: Mechanism-driven biomarkers to guide immune checkpoint blockade in cancer therapy. Nat Rev Cancer 16: 275-287, 2016.

36. Karwacz K, Bricogne C, MacDonald D, Arce F, Bennett CL, Collins M and Escors D: PD-L1 co-stimulation contributes to ligand-induced $\mathrm{T}$ cell receptor down-modulation on CD8+ T cells. EMBO Mol Med 3: 581-592, 2011.

37. Chen G, Huang AC, Zhang W, Zhang G, Wu M, Xu W, Yu Z, Yang J, Wang B, Sun H, et al: Exosomal PD-L1 contributes to immunosuppression and is associated with anti-PD-1 response. Nature 560: 382-386, 2018

38. Flies DB and Chen L: The new B7s: Playing a pivotal role in tumor immunity. J Immunother 30: 251-260, 2007.

39. Vermeer DW, Coppock JD, Zeng E, Lee KM, Spanos WC, Onken MD, Uppaluri R, Lee JH and Vermeer PD: Metastatic model of HPV+ oropharyngeal squamous cell carcinoma demonstrates heterogeneity in tumor metastasis. Oncotarget 7: 24194-24207, 2016.

40. Stack EC, Wang C, Roman KA and Hoyt CC: Multiplexed immunohistochemistry, imaging, and quantitation: A review, with an assessment of Tyramide signal amplification, multispectral imaging and multiplex analysis. Methods 70: 46-58, 2014.

41. Feng Z, Puri S, Moudgil T, Wood W, Hoyt CC, Wang C, Urba WJ, Curti BD, Bifulco CB and Fox BA: Multispectral imaging of formalin-fixed tissue predicts ability to generate tumor-infiltrating lymphocytes from melanoma. J Immunother Cancer 3: 47, 2015

42. Feng Z, Jensen SM, Messenheimer DJ, Farhad M, Neuberger M, Bifulco CB and Fox BA: Multispectral imaging of T and B cells in murine spleen and tumor. J Immunol 196: 3943-3950, 2016.

43. Liu J, Yuan Y, Chen W, Putra J, Suriawinata AA, Schenk AD, Miller HE, Guleria I, Barth RJ, Huang YH and Wang L: Immune-checkpoint proteins VISTA and PD-1 nonredundantly regulate murine T-cell responses. Proc Natl Acad Sci USA 112: 6682-6687, 2015

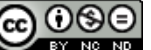

This work is licensed under a Creative Commons Attribution-NonCommercial-NoDerivatives 4.0 International (CC BY-NC-ND 4.0) License. 